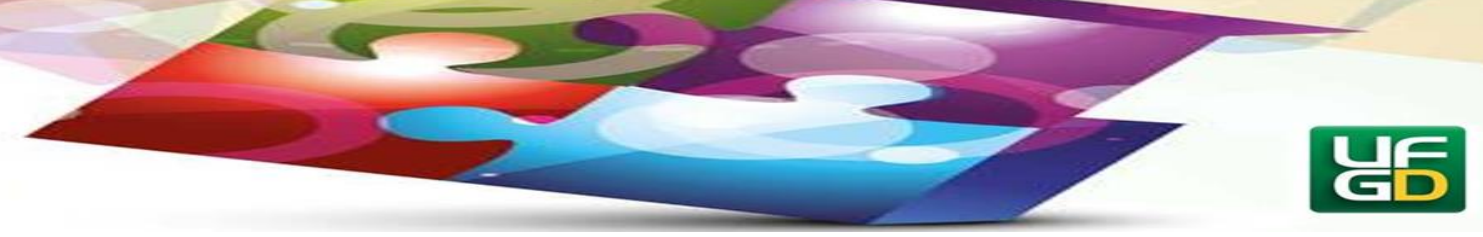

\title{
ENSINO DE FÍSICA MODERNA EM UM PROCESSO DE SALA DE AULA INVERTIDA: REFLEXÕES E POTENCIALIDADES
}

\section{MODERN PHYSICS TEACHING IN A CLASSROOM PROCESS INVERTED: REFLECTIONS AND POTENTIALITIES}

\begin{abstract}
Resumo: esse artigo apresenta resultados de uma investigação sobre uma proposta de sala de aula invertida em uma aula sobre ensino de Dilatação de Espaço Tempo de Einstein, abordado em Física Moderna, realizada com uma turma de nove alunos concluintes do Ensino Médio Integrado, da rede pública federal de ensino, em horário extraclasse. O professor envia material instrucional aos estudantes antes da realização da aula, de modo a utilizar, de forma mais ativa e dinâmica, seu tempo em sala. No dia anterior à aula, ocorreu pane no sinal de Internet da cidade, o que dificultou muito o acesso dos estudantes ao material enviado pelo professor. Foi aplicado um questionário ao final da aula, sobre o uso da metodologia e a aprendizagem do conteúdo proposto. A análise dos dados evidenciou que o uso desta metodologia pode proporcionar maior independência do aluno na construção do conhecimento, bem como um novo agir docente quanto ao planejamento, desenvolvimento e avaliação da aprendizagem dos estudantes, bem como saber lidar com os problemas técnicos de ordem tecnologia que estão presentes nas atividades realizadas em sala de aula.
\end{abstract}

Palavras-chave: Dilatação Espaço Tempo de Einstein. Ensino de Física. Flipped Classroom. Tecnologias Digitais.

\begin{abstract}
: this article presents the results of an investigation of an inverted classroom proposal in a class on Einstein Space Time Dilatation, addressed in Modern Physics, carried out with a class of nine graduates from Integrated High School, of the network public education, in extraclass hours. The teacher sends instructional material to the students prior to the class, in order to use their time in the classroom more actively and dynamically. The day before the class, there was a crash in the city's Internet signal, which made it very difficult for students to access the material sent by the teacher. A questionnaire was applied at the end of the lesson, about the use of the methodology and the learning of the proposed content. The analysis of the data showed that the use of this methodology can provide greater independence of the student in the construction of knowledge, as well as a new teaching role in the planning, development and evaluation of student learning, as well as how to deal with technical problems of technology order which are present in the activities carried out in the classroom.
\end{abstract}

\footnotetext{
${ }^{1}$ Mestre em Ensino de Física pela Universidade Federal de Mato Grosso do Sul (UFMS), campus Campo Grande. Docente do Instituto Federal de Mato Grosso do Sul. Doutorando do Programa de Pós-Graduação em Educação, na UFMS. Artigo orientado pela Prof. Dra. Suely Scherer. E-mail: ronaldo.silva@ifms.eud.br.
} 


\section{HORIZONTES - REVISTA DE EDUCAÇÃO}

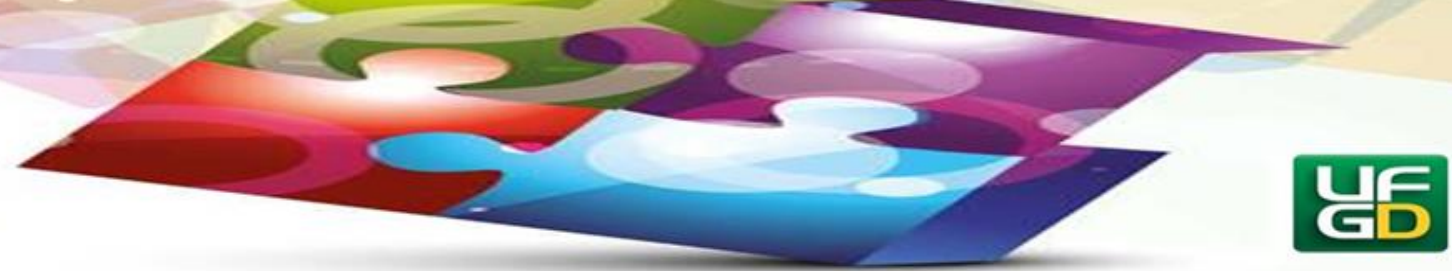

Keywords: Einstein Space Time Dilation. Teaching Physics. Flipped Classroom. Digital Technologies.

\section{Introdução}

Desafios e necessidades de enfrentamento estão postos em todas as esferas do ensino. São dificuldades que potencializam a dicotomia existente entre o esvaziamento das salas de aula, por causas financeiras e/ou pedagógicas dos estudantes e a necessidade da inserção crescente de estudantes, não mais puramente para formação de mão de obra para o mercado de trabalho, mas, sobretudo de pessoas atuantes dentro de uma economia globalizada (TAPSCOTT; WILLIAMS, 2010).

Esse contexto requer uma educação básica e superior que se utilize de novas metodologias de ensino, buscando formar profissionais colaborativos, exploradores, investigadores, mesmo em meio a todas as limitações conceituais e temporais dos estudantes (VALENTE, 2007).

Aparentemente voltada ao Ensino Superior a proposta da sala de aula invertida é uma metodologia que coloca o aluno em ação, e como descrito por Valente (2014), é uma metodologia que pode ser aplicada a sala de aula de Ensino Médio. Também conhecida inicialmente como inverted classrom, a metodologia da sala de aula invertida foi proposta por Lage, Platt e Treglia, no ano 2000, a partir de uma atividade desenvolvida, no ano de 1996, numa disciplina de Microeconomia da Universidade de Miami, em Ohio, Estados Unidos (VALENTE, 2014).

Essa metodologia se refere predominantemente à ordem como as atividades pedagógicas são realizadas dentro do processo pedagógico. Nela, o educando estuda o material enviado pelo professor antes da aula. De posse de informações prévias referentes ao conteúdo, o tempo da sala de aula será utilizado para resoluções de problemas, discussões de tarefas e fases de projetos, realização de experimentos, esclarecimento de dúvidas. Estas ações tendem a transformar a sala de aula em um espaço ativo e produtivo de conhecimento mútuo, ao invés de um local puramente de transmissão de saberes do professor para o educando (EDUCAUSE, 2012). 


\section{HORIZONTES - REVISTA DE EDUCAÇÃO}

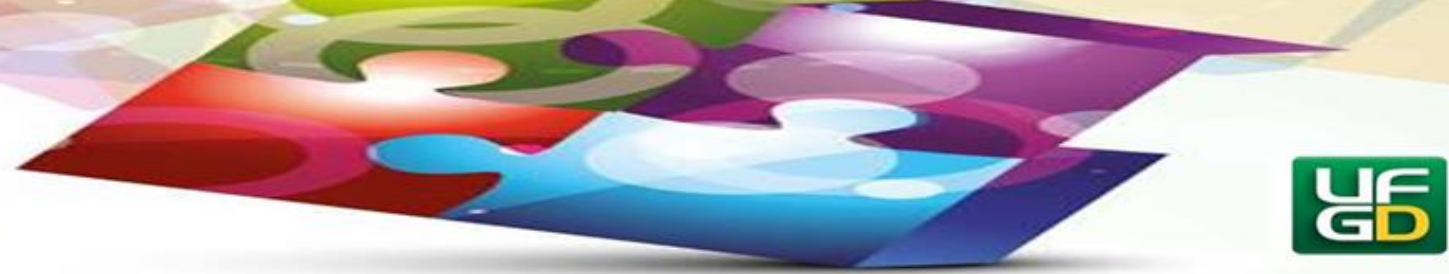

Foram publicações a partir de 2010, em importantes mídias como o The New York Times e Chronicle of Higher Education, que popularizaram o termo flipped classroom, ao invés de inverted classroom, divulgando seu uso em diferentes níveis escolares (VALENTE, 2014). Algumas disciplinas do Ensino Médio brasileiro, como Literatura, História, Filosofia e Sociologia já fazem uso desta metodologia, mesmo às vezes sem conhecimento do termo, uma vez que os estudantes leem textos e livros antes da aula presencial, o que geralmente não acontece nas aulas de disciplinas da área de Exatas, nas quais geralmente acontece a transmissão direta de informações do professor para o aluno.

Nesse contexto, neste artigo analisamos uma aula de Física, que ocorreu em um horário extraclasse, com nove alunos concluintes do Ensino Médio, utilizando a metodologia da sala de aula invertida.

\section{Aula de Física em uma proposta de Sala de Aula Invertida}

A investigação foi realizada a partir da proposta de uma atividade de Física a uma turma concluinte do Ensino Médio Integrado, da rede pública federal de ensino, matriculados na disciplina de Física 6.

Ao buscar a abordagem de um tema de aula que despertasse o interesse dos estudantes e ao considerar a falta de tempo para o ensino de Física Moderna, considerando apenas os 03 tempos de aula semanais, com 45 minutos cada, o professor, escolheu o conteúdo de Dilatação Espaço Tempo de Einstein. Foi proposto aos estudantes o horário de aula em um sábado, das $8 \mathrm{~h} 00$ às $9 \mathrm{~h} 30 \mathrm{~min}$ da manhã. Inscreveram-se para a aula 13 estudantes com idades entre 16 e 18 anos. No entanto, apenas nove alunos compareceram à aula.

\section{A seleção de materiais}

A seleção de material instrucional a ser encaminhado aos alunos, previamente a aula, não foi uma tarefa fácil. A opção inicial do professor foi por não produzir material, mas usar textos e vídeos ddisponíveis na internet. Por se tratar de assunto de Física Moderna, solicitando um novo olhar do educando para compreensão do conteúdo, agora não mais calcado na Física Clássica, o professor buscou materiais de fácil leitura e compreensão. 


\section{HORIZONTES - REVISTA DE EDUCAÇÃO}

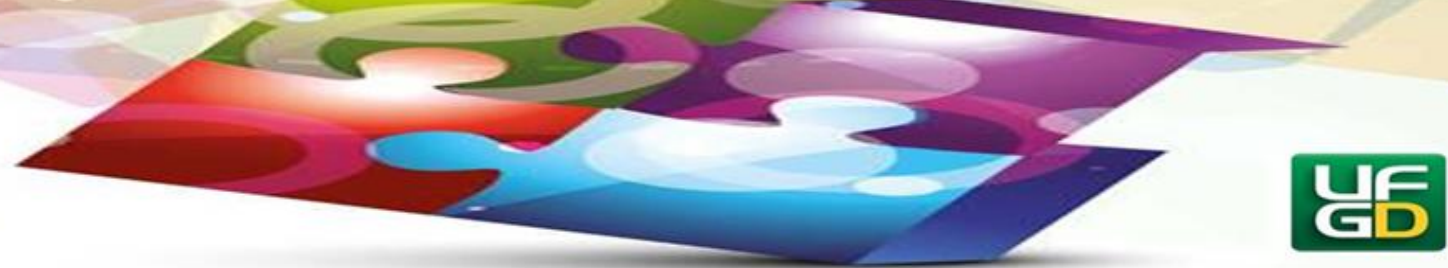

Essa tarefa não foi fácil, pois os textos encontrados continham excesso de fórmulas, e isto poderia dificultar o entendimento dos estudantes. O texto selecionado e encaminhado aos estudantes é intitulado "Dilatação de tempo", de autoria de Batista (2006).

O texto enviado aos estudantes aborda a medição do tempo de um mesmo evento medido por dois observadores. O evento analisado considera um raio de luz sendo emitido com velocidade da luz ( $c=3.10^{8} \mathrm{~m} / \mathrm{s}$ ) por uma lâmpada, localizada no piso de um vagão, subindo perpendicularmente até ser refletido por um espelho localizado a uma distância "d" do piso, retornando à lâmpada, como apresentado na Figura1. Dessa forma, o tempo $\Delta \mathrm{t}^{\prime}$ de ida e volta, medido pelo observador O', localizado dentro do vagão, seria “c / 2d”. Estando o vagão em repouso ou movimento, a percepção deste caminho realizado pela luz e a medição do tempo total do movimento, para este observador, não sofrem alterações.

Figura 1: Percepção para observador interno

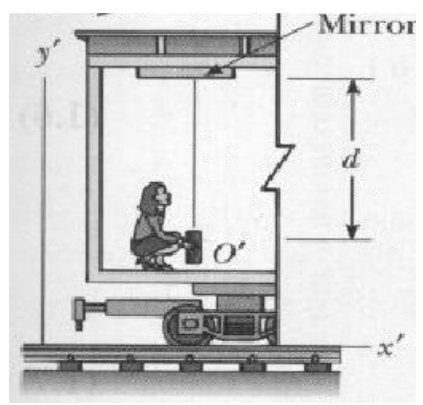

Fonte: (Batista, 2006)

Localizado externamente ao vagão, um observador $\mathrm{O}$, mede o mesmo tempo e observa o padrão de percurso do raio de luz, caso o vagão estivesse em repouso. Entretanto, considerando que o vagão se movimente para a direita com velocidade "v", a percepção do observador externamente localizado, seria alterada. 


\section{HORIZONTES - REVISTA DE EDUCAÇÃO}

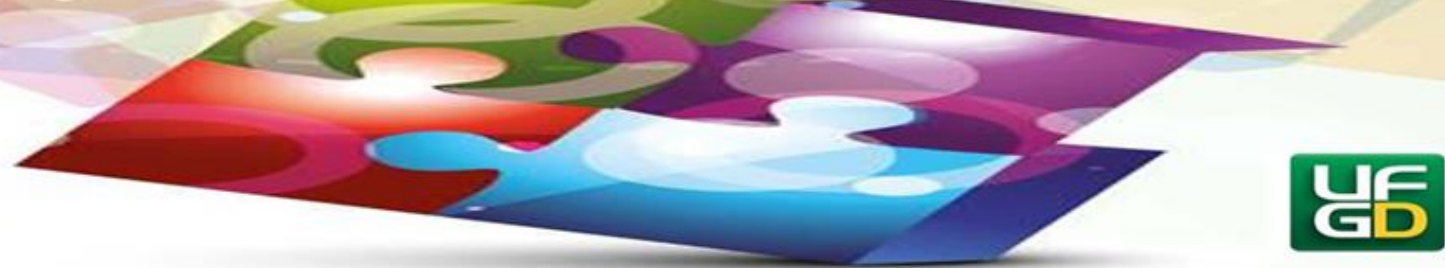

Figura 2: Percepção para observador externo

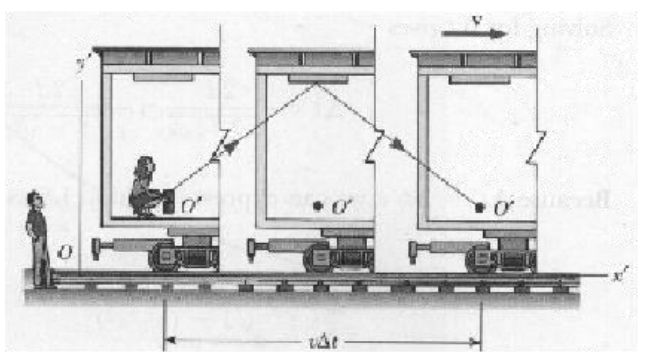

Fonte: (Batista, 2006).

O raio de luz seria emitido pela lâmpada, incidiria no espelho, que já teria se deslocado, e retornaria à lâmpada percorrendo percursos não mais perpendiculares em relação à linha horizontal, cuja distância denominaremos de "L". Assim, o tempo $\Delta$ t medido por este observado igual a "c / 2L", como evidencia-se na Figura 2.

O texto enviado aos estudantes, por processo de triangulação compara estes dois tempos e conclui que surge um fator corretivo entre os dois tempos medido, como segue:

$$
\Delta t=\frac{1}{\sqrt{1-\frac{v^{2}}{c^{2}}}} \cdot \Delta t^{\prime}
$$

Assim, considerando situações em que a velocidade "v" do vagão é pequena comparada à velocidade da luz, o termo " $\mathrm{v}^{2} / \mathrm{c}^{2}$ ", pode ser desprezado e desta maneira tem-se que $\Delta \mathrm{t}=\Delta \mathrm{t}$ ', ou seja, os tempos medidos para os observadores $\mathrm{O}$ e O' são iguais. Entretanto, se a velocidade "v" do vagão já não for desprezível comparada à velocidade da luz, tem-se que $\Delta \mathrm{t}$ sendo maior que $\Delta \mathrm{t}$ ', ou seja, o tempo medido pelo observador externo é maior (e diferente) que o do observador interno.

No texto enviado aos estudantes discute-se o aparecimento deste termo, conhecido como “fator de correção de Lorentz". Os textos ainda contêm, no seu final, um exercício resolvido considerando a dilatação do tempo. 


\section{HORIZONTES - REVISTA DE EDUCAÇÃO}

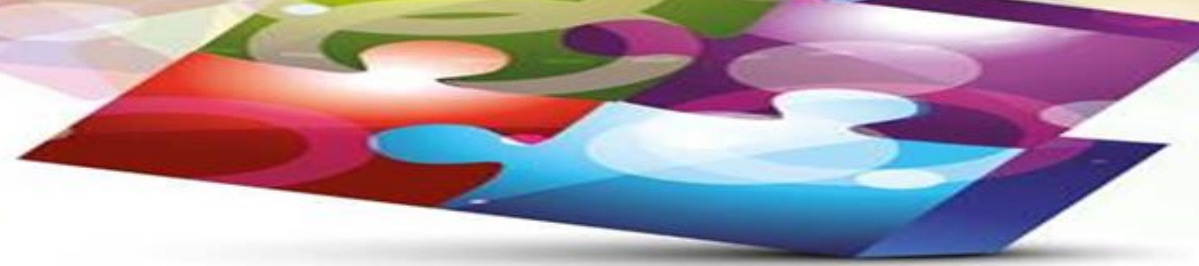

Outra tarefa difícil foi a de encontrar um vídeo, disponível na Web e de acesso gratuito, que abordasse a temática "Dilatação de tempo". Muitos dos vídeos disponíveis apresentavam professores ministrando aula on-line, em formato expositivo, fazendo abordagem de deduções diretas de fórmulas. Por fim, foi encaminhado aos estudantes o vídeo chamado "Dilatação do Tempo \#52 TempoNerd", abordando a questão do "paradoxo dos gêmeos", disponível em $<$ https://www.youtube.com/watch?v=sZsDSD2y900\&t=87s >. No vídeo enviado aos alunos analisa-se o paradoxo dos gêmeos, exemplo comumente usado para abordagem do tema da aula, sem demonstração de fórmula, tratando da medição do tempo por cada um deles, em uma situação em que um deles fica na Terra e o outro faz uma viagem espacial, em uma nave em alta velocidade.

Além dos materiais, foi encaminhada um exercício a ser resolvido por eles, antes da aula que dizia: "Considere dois gêmeos idênticos, Renato e Luís. Suponha que enquanto Renato permaneça na Terra, Luís faça uma viagem para a estrela alfa da constelação do Centauro (distante 4 anos luz da Terra), com uma espaçonave que viaja com $80 \%$ da velocidade da luz. Qual a diferença de idade entre os dois após o retorno de Luís?’. Foi ainda proposto um desafio aos estudantes: "Construa de forma análoga à dilatação do tempo, a definição da dilatação do espaço".

\section{A sala de aula invertida em ação}

Para a aula no sábado, o material foi encaminhado na quarta-feira anterior, à noite, ao e-mail e ao grupo de Whatsapp da turma. O texto foi disponibilizado em formato PDF e o vídeo com link do site Youtube, buscando facilitar a leitura dos arquivos pelos estudantes, em seus computadores e até mesmo celulares. Vale mencionar que os alunos participantes da aula não haviam tido contato com esse conteúdo anterior a essa experiência.

Na sexta-feira, dia anterior a aula, ocorreu problema de acesso ao sinal da internet na cidade. No sábado, os estudantes participantes chegaram mais cedo à escola, buscando acesso à rede de Internet da Instituição, que também ainda apresentava dificuldade de acesso. De modo geral, eles não tiveram a interação planejada e necessária com o texto e o vídeo anterior a aula, conforme prevê a proposta da sala de aula invertida. 


\section{HORIZONTES - REVISTA DE EDUCAÇÃO}

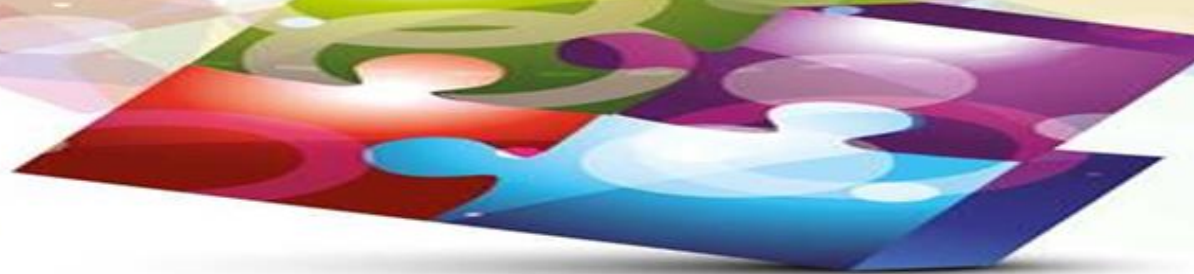

Buscando resolver o problema da falta de acesso ao material da aula, o professor entregou um resumo do texto, elaborado por ele mesmo, contendo ideias, apresentação das equações e exercícios que deveriam ser resolvidos pelos estudantes. Foi dado um tempo inicial aos estudantes para cumprimento desta etapa, em duplas, mas mesmo assim eles relataram dificuldade em entender o texto e solucionar as atividades propostas.

Somente após as explicações realizadas na lousa pelo professor sobre o conteúdo, os estudantes realizaram a tarefa proposta e a questão desafio. Maiores interações não foram possíveis devido ao fator tempo disponibilizado para a atividade, visto que os estudantes não poderiam permanecer em sala depois do horário acordado. No final da aula foi entregue um questionário com 10 questões aos estudantes, sobre a metodologia e conteúdo da aula. Os resultados serão apresentados e descritos nos gráficos a seguir.

Gráfico1: A leitura de um texto é capaz de fazer entender o conteúdo?

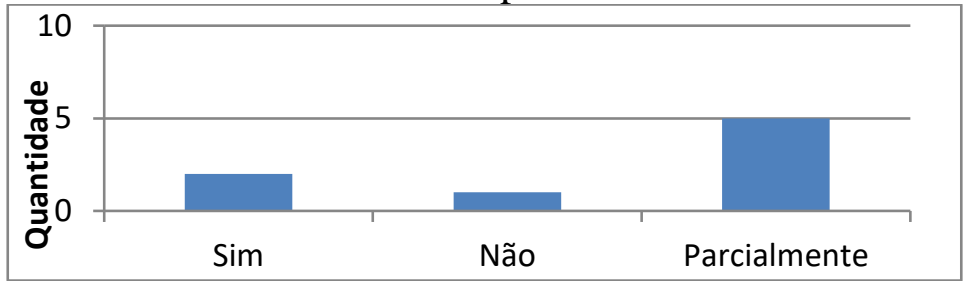

Fonte: o autor.

Gráfico 2: A abordagem de um assunto novo é mais fácil com:

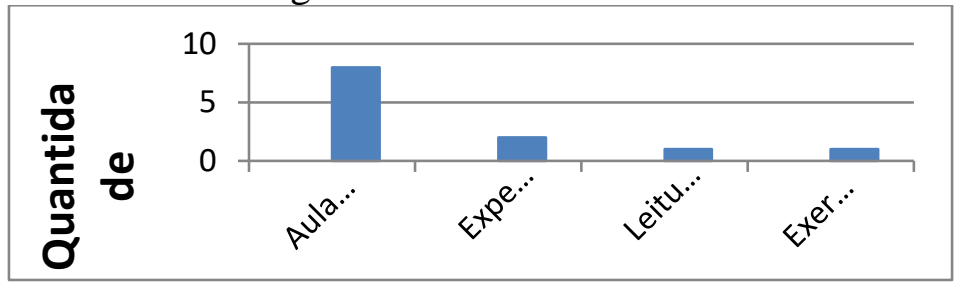

Fonte: o autor.

Gráfico 3: A sala de aula invertida, em relação a sua aprendizagem inicial do assunto

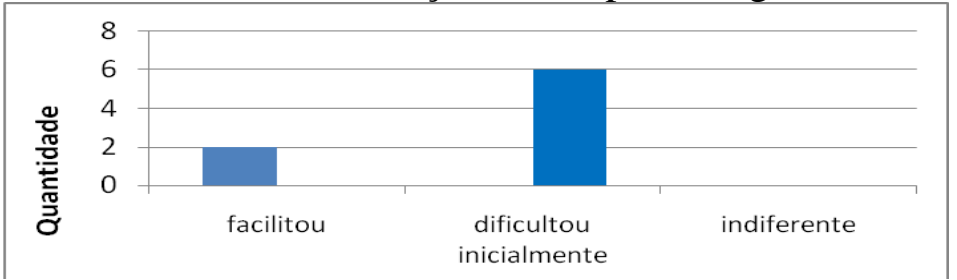

Fonte: o autor. 


\section{HORIZONTES - REVISTA DE EDUCACATO}

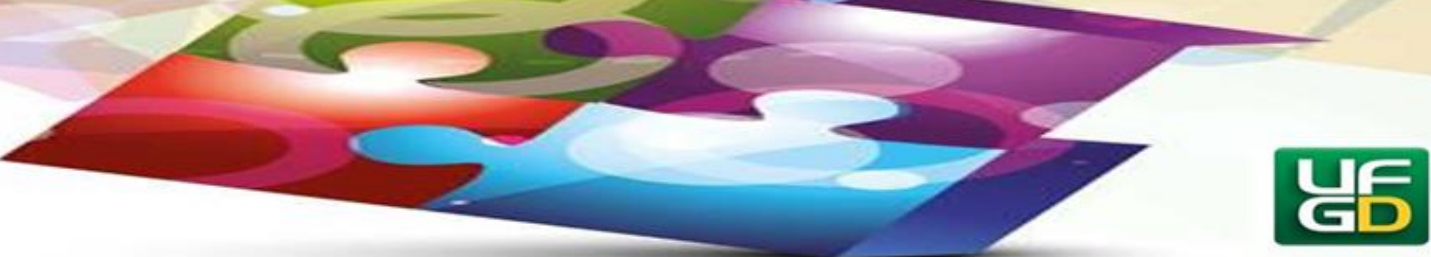

Gráfico 4: A sua compreensão do assunto com o uso da Sala de aula Invertida

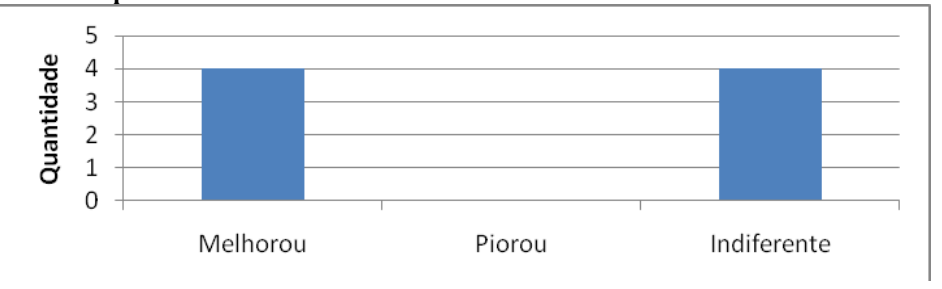

Fonte: o autor.

Gráfico 5: O uso da sala de aula invertida deveria ocorrer

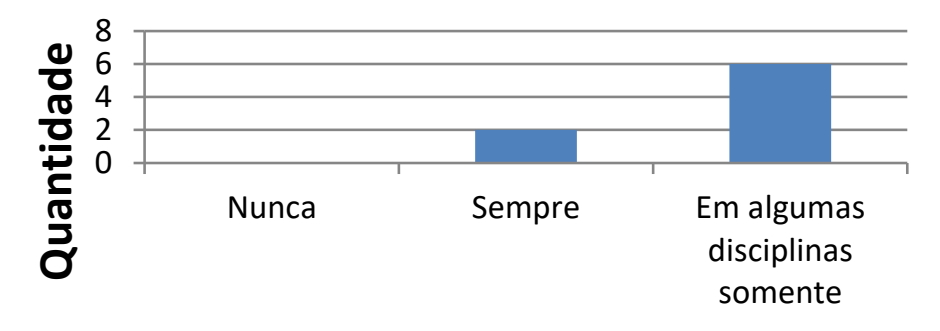

Fonte: o autor.

Gráfico 6: O que mais dificultou o entendimento do assunto pela leitura do texto

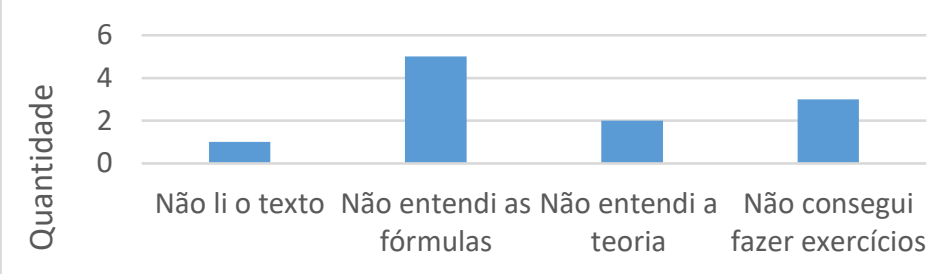

Fonte: o autor.

Gráfico 7: Em qual disciplina você considera mais indicado o uso da Sala de Aula Invertida?

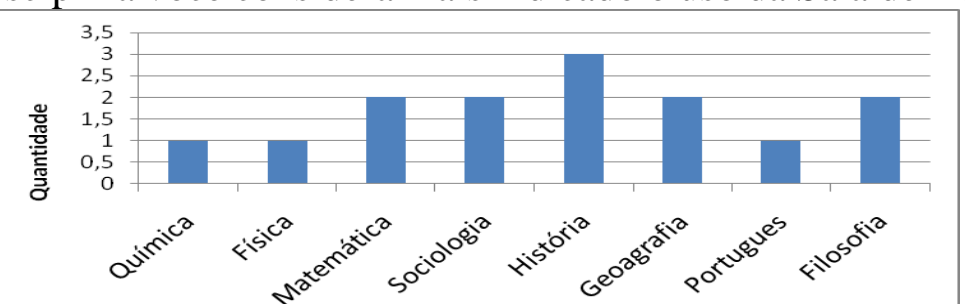

Fonte: o autor. 


\section{HORIZONTES - REVISTA DE EDUCAÇÃO}

Gráfico 8: Qual seu sentimento inicial em relação à leitura do texto?

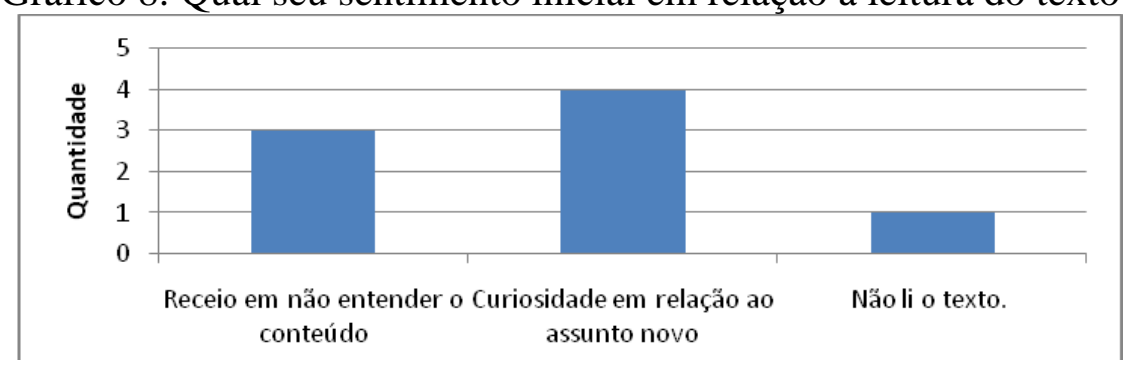

Fonte: o autor.

Gráfico 9: Qual seu sentimento após a leitura do texto?

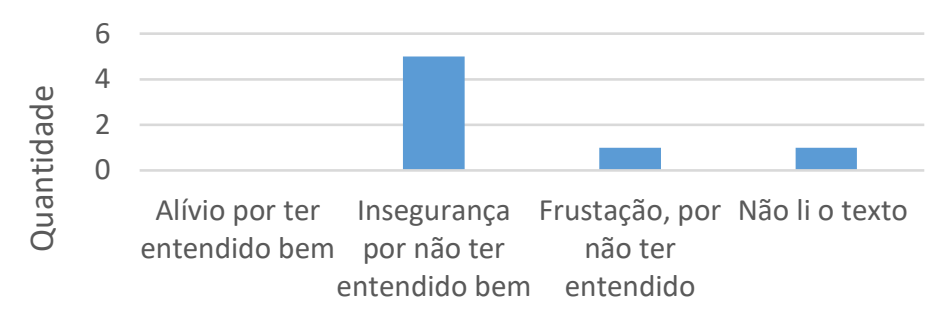

Fonte: o autor.

Após os alunos responderem ao questionário, eles iniciaram uma discussão sobre a quebra da Simultaneidade em Física Moderna. Mesmo sem muito tempo disponível, o professor montou um quadro comparando a mudança conceitual entre as Físicas Clássica e Moderna, conforme segue:

\begin{tabular}{|l|l|l|l|}
\hline \multicolumn{2}{|c|}{ Quadro 1 - Comparativo } \\
\hline Espaço & \multirow{2}{*}{ Física Clássica } & & \multicolumn{2}{c|}{ Física Moderna } \\
\cline { 1 - 1 } Tempo & & Espaço & \multirow{2}{*}{ Conceitos relativos } \\
\cline { 1 - 1 } Simultaneidade & & Tempo & \\
\cline { 3 - 4 } & & Simultaneidade & Conceito absoluto \\
\hline Velocidade & Conceito relativo & Velocidade & \\
& & & \\
& & & \\
& & &
\end{tabular}

Fonte: o autor. 


\section{HORIZONTES - REVISTA DE EDUCAÇÃO}

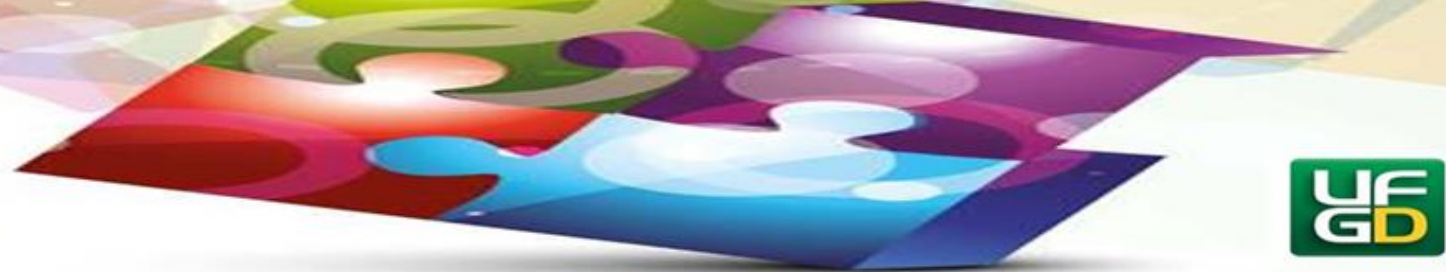

Figura 3: Análise da simultaneidade da morte dos passarinhos

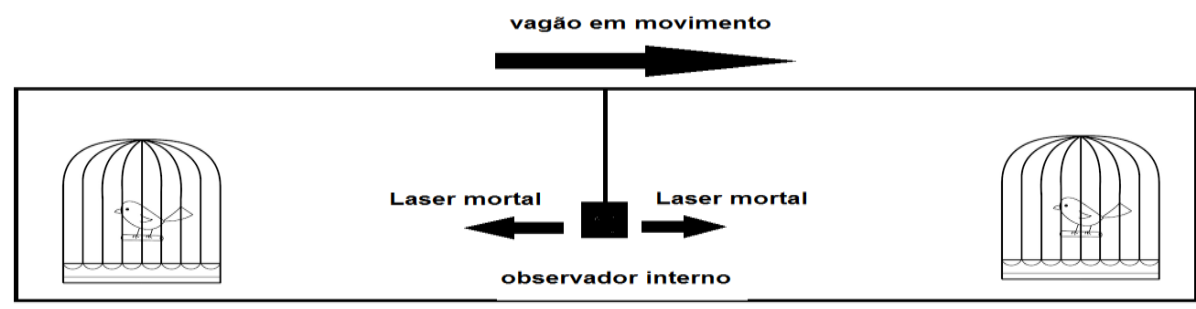

observador externo

Fonte: o autor.

Foi explicado aos estudantes que em Física Clássica o espaço, o tempo e a simultaneidade de um fenômeno são invariantes, ou seja, diferentes observadores chegam à mesma conclusão quando analisam determina situação. Entretanto, o conceito de velocidade é relativo, por exemplo, uma pessoa parada na esquina, está em repouso em relação a sua carteira, mas está em movimento em relação a um carro que passou por ela, visto que o tempo passa e a distância entre eles sofre alteração. Já em Física Moderna, considerando que a velocidade da luz passa a ter valor absoluto, o espaço, o tempo e a simultaneidade passam a ser relativos.

Sobre o Quadro 1, um dos estudantes, que denominaremos de Estudante A, questionou: "Professor, quanto ao espaço e o tempo serem medidos com valores diferentes, sofrendo dilatação, eu entendi com o caso dos gêmeos, que o que fica na Terra medirá um tempo maior que aquele que foi em viagem em uma nave espacial. Mas não consigo entender a quebra da simultaneidade. Como algo pode acontecer e não acontecer ao mesmo tempo?”.

A partir dessa questão, o professor levantou a questão apresentada na Figura 3. Segue o diálogo ocorrido entre professor a alunos:

Professor: "Dois passarinhos estão presos em gaiolas localizadas a mesma altura do chão, em paredes opostas de um vagão que se move com certa velocidade para a direita e a mesma distância de um laser mortal e se propaga com a velocidade da luz. Ao ser disparado o laser, qual a conclusão que chegam dois observadores: um interno e o outro externo ao vagão quanto à morte dos passarinhos?". 


\section{HORIZONTES - REVISTA DE EDUCAÇÃO}

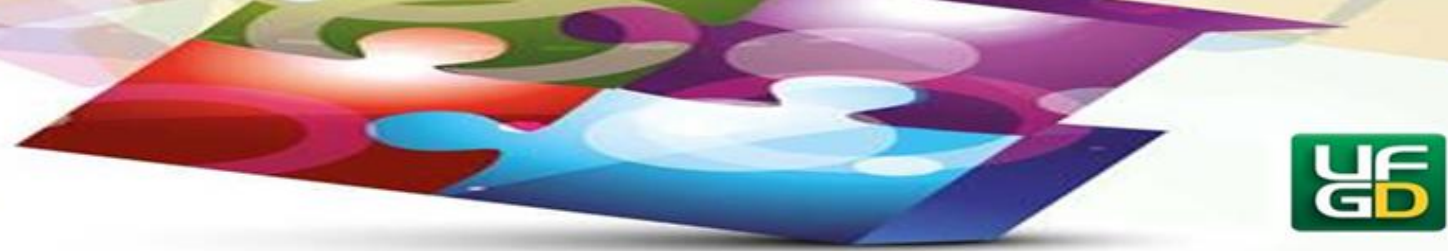

Educando B: "Bem, se o vagão estivesse parado, os dois observadores veriam a morte dos passarinhos ao mesmo tempo".

Educando $C$ : "Estando o vagão em movimento, o observador de dentro do vagão veria a mesma coisa, mesmo momento de morte para os dois passarinhos". Mas, o observador de fora, veria o passarinho da esquerda morrer primeiro porque ele foi atrás de encontro ao laser e somente depois é que o passarinho da direita morreria, pois ele meio que foge do laser mortal. É isto professor?".

Educando D: "ué, mas quem está correto então?"

Educando A: “depende onde você está, dentro ou fora do vagão, ambos estão corretos". Este é somente um fragmento do diálogo ocorrido. Por conta do horário, os estudantes precisaram ir para outra sala e, mesmo de longe, ainda se ouvia a conversa deles sobre o assunto.

A análise deste momento final da aula evidencia a empolgação da turma quanto ao assunto abordado, potencializa o uso da Sala de Aula Invertida pelo professor, por meio de textos e vídeos que provoquem a curiosidade dos alunos. Não encontrando materiais didáticos prontos que atendem exatamente ao objetivo da aula, cabe ao professor elaborar, atentando à linguagem usada e ao conhecimento dos alunos.

\section{Considerações finais}

A maneira como o conteúdo foi apresentado no texto parece ter dificultado a compreensão do mesmo por alguns alunos. Evidenciou-se, pela análise dos dados apresentados nos gráficos, uma insegurança dos alunos quanto à capacidade de compreensão independente da explicação inicial do professor, na abordagem de um assunto novo em sala de aula.

Nesse sentido, o professor precisa ficar atento ao conteúdo e linguagem presentes no texto enviado uma vez que, estando aquém da capacidade do entendimento dos estudantes pode ser desmotivador. O professor pode adaptar textos existentes ou até mesmo escrever novo texto, inserindo agentes convidativos à leitura, não deixando o texto tão técnico, buscando despertar o gosto pela leitura no educando. Assim poderá também solicitar de seus estudantes leitores a produção de textos e vídeos científicos, buscando identificar o desenvolvimento de linguagem científica dos alunos, utilizando novas ferramentas de ensino, aprendizagem e avaliação. 


\section{HORIZONTES - REVISTA DE EDUCAÇÃO}

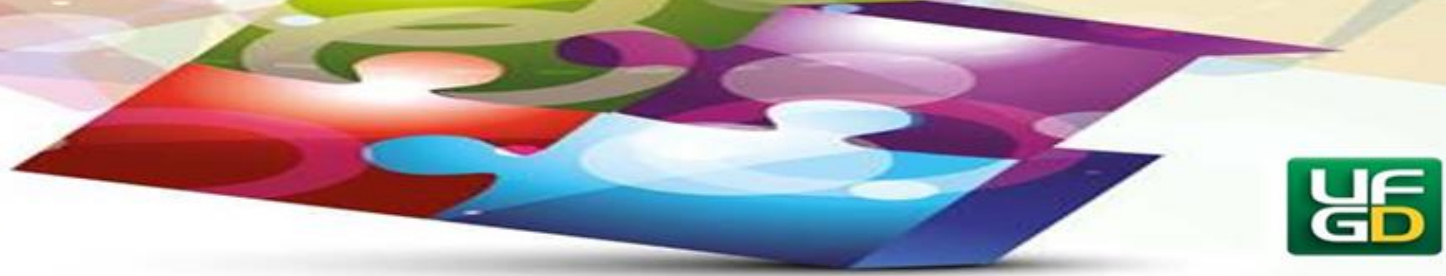

Da mesma forma, embora vídeos e simulações estejam disponíveis na Internet, no caso de não adequados à proposta do professor, caberá produzir novos vídeos e simulações aos seus estudantes, adequando a linguagem e a discussão teórica conceitual à realidade da turma.

Os dados levantados nesta aula e o aparente interesse dos alunos em continuar a discussão de situações de Física Moderna, potencializam o uso desta metodologia, a sala de aula invertida, de forma a favorecer a construção do conhecimento.

Por fim, observou-se que no uso da Sala de Aula Invertida o papel do professor é avivado e o educando passa a ter ação destacada no processo de aprender. Ao professor cabe avaliar o que os estudantes leram, como leram, o que e como compreenderam o conteúdo a ser explorado na aula. Quanto ao educando observou-se que os alunos envolvidos na pesquisa precisariam ainda desenvolver a autonomia para estudar e criar estratégias para estudar os materiais encaminhados para estudo antes da aula. Com o tempo, a aula poderá deixar de ter caminho de mão única de transmissão de informação, podendo avançar para momentos de debate e produção coletiva de alunos e professor.

Assim, a sala de aula invertida apresenta-se como uma metodologia com possibilidades de planejar e executar aulas e avaliar os estudantes, em aulas que os incluem como sujeitos realmente ativos nas aulas.

\section{Referências}

BATISTA, R.C. Dilatação do tempo. 2006. Disponível em:

<http://plato.if.usp.br/ fma0374d/aula2/node4.html>. Acesso em 13 de Jun. de 2018.

EDUCAUSE: Things you should know about flipped classrooms. 2012. Disponível em: <http://search.proquest.com/openview/616e91b3df376d82fd5d30c598c665f3/1?pqorigsite $=$ gscholar\&cbl=29704> . Acesso em: 13 Jun. 2017.

TAPSCOTT, D.; WILLIAMS, A. D. Innovating the 21st-Century University: It's Time! Educause Review, January/February 17-29, 2010. Disponível em: <http://www.educause.edu/ir/library/pdf/ERM1010.pdf >. Acesso em: 13 de Jun. de 2018.

VALENTE, J. A. Blended learning e as mudanças no ensino superior: a proposta da sala de aula invertida. Educar em Revista, p. 79-97, 2014.

VALENTE, J. A. A crescente demanda por trabalhadores mais bem qualificados: a capacitação para a aprendizagem continuada ao longo da vida. In: VALENTE, J. A. 


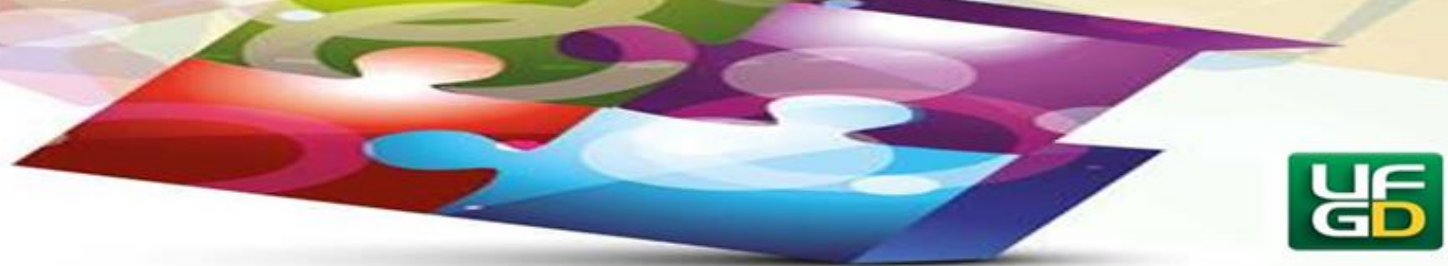

MAZZONE, J.; BARANAUSKAS, M. C. C. (Orgs.). Aprendizagem na era das tecnologias digitais. São Paulo: Cortez; FAPESP, 2007.

Enviado: 19/12/2018.

Aceito: 24/05/2019. 